Original Research Article

\title{
Comparison of efficacy and safety of ketoprofen patch versus diclofenac patch as post-operative analgesic in hysterectomy patients
}

\author{
Seema Rani $^{1}$, Meenakshi Savant ${ }^{1} *$, Rajiv Mahendru², ${ }^{2}$ ranav Bansal $^{3}$
}

\begin{abstract}
${ }^{1}$ Department of Pharmacology,
${ }^{2}$ Department of Obstetrics and Gynaecology, ${ }^{3}$ Department of Anaesthesiology, BPS GMC (W), Khanpur Kalan, Sonepat, Haryana, India
\end{abstract}

Received: 14 August 2019

Revised: 13 August 2019

Accepted: 21 September 2019

*Correspondence to:

Dr. Meenakshi Savant,

Email: meenakshi.savant@ yahoo.com

Copyright: () the author(s), publisher and licensee Medip Academy. This is an openaccess article distributed under the terms of the Creative Commons Attribution NonCommercial License, which permits unrestricted noncommercial use, distribution, and reproduction in any medium, provided the original work is properly cited.

\begin{abstract}
Background: The objective of the study was to compare the efficacy and safety of ketoprofen patch versus diclofenac patch as post-operative analgesic in hysterectomy patients.

Methods: The study was a prospective, single blind, randomized, comparative interventional clinical study conducted in a tertiary care hospital. Sixty female patients were randomly allocated to receive either ketoprofen or diclofenac patch 1 hour prior to the hysterectomy. Pain was assessed postoperatively after an interval of every four hours for 24 hours using visual analogue scale (VAS) and verbal rating scale (VRS).

Results: In ketoprofen group, mean VAS was (2.92 \pm 0.11$)$ significantly low as compared to diclofenac group $(3.25 \pm 0.14)$. The mean VRS score in group ketoprofen $(1.62 \pm 0.22)$ was low as compared to group diclofenac $(1.83 \pm 0.16)$. Safety analysis revealed no apparent serious adverse events. Inj. Paracetamol 1 gm i.v was given as rescue analgesic to the patients in whom VRS $>2$ and VAS $>5$ was noted. Data were analysed using unpaired student's t-test.

Conclusions: Transdermal patches are very convenient to use and causes less discomfort as compared to traditional routes of drug delivery. Ketoprofen patch was found better in providing analgesia after hysterectomy as compared to diclofenac patch with lesser side effects.
\end{abstract}

Keywords: Transdermal, Verbal rating scale, Visual analogue scale

\section{INTRODUCTION}

The international association for study of pain (IASP) has defined pain as "an unpleasant sensory and emotional experience which is associated with actual or potential tissue damage". ${ }^{1}$ Pain is not related to only physical sensation but it is also influenced by attitude, belief, personality and social factors. It also affects emotional and mental wellbeing. Pain is the most common reason for which people seek medical help. ${ }^{2,3}$ The pain of surgery is nociceptive, acute in onset, short duration and subsides when the damaged tissue heals. ${ }^{4}$ Post-operative pain if poorly treated can lead to suffering, anxiety, depression (psychological effects), hypertension, tachycardia, myocardial infarction (stress effects), chest infections and delayed recovery (immobility). Effective pain control can attenuate all the above adverse effects and enhance well-being of the patients. Hysterectomy is the surgical operation done by the gynecologists in which uterus is removed. It is recommended as a last resort to correct certain intractable uterine/reproductive system diseases. Post-operative pain after hysterectomy originates from somatosensory pain of the incision site and from viscero-peritoneal pain of inflammatory tissues. ${ }^{5}$ It can be managed with intermittent systemic analgesics such as opioids, ketamine, non-steroidal antiinflammatory drugs (NSAID), $\alpha-2$ agonist or continuous infusion of a mixture of drugs acting through different 
mechanisms. The drugs which are used frequently for relieving pain belongs to different classes like NSAIDs, opioids, glucocorticoids, local anesthetics, $\alpha-2$ agonists, ketamine and gabapentanoids. ${ }^{6}$ Mostly these drugs are given orally or parenterally. Transdermal route is an innovative method of drug administration which is becoming very popular recently. NSAIDs are frequently used for pain management in various circumstances. The commonly used drugs are diclofenac, ibuoprofen, ketorolac, ketoprofen, mephenamic acid, indomethacin etc.

Diclofenac is an aryl- acetic acid derivative and ketoprofen is propionic acid derivative. Oral, i.v., i.m. preparations of diclofenac and ketoprofen are used as postoperative analgesic. Several researchers found that the transdermal preparation of these drugs is more efficacious than oral dosage form with less side effects. The present study was planned in the view of the fact that analgesic drugs are given through different routes as postoperative analgesic but still there is a search for an ideal drug and route that provides maximum analgesia, minimum side effects and improves patient compliance. Various literatures have been searched but no study was found comparing the efficacy and safety of these patches in post-hysterectomy patients. Therefore present study was undertaken in patients undergoing hysterectomy with the objective to compare the efficacy and safety of transdermal ketoprofen patch vs. transdermal diclofenac patch in post-operative hysterectomy patients.

\section{METHODS}

\section{Study design}

This study was conducted as a prospective, single blind randomized, comparative clinical study from May 2018 to April 2019 by the Department of Pharmacology in collaboration with the Department of Obstetrics \& Gynecology and Department of Anesthesiology at B.P.S. Govt. Medical College for Women (a tertiary care hospital in the state of Haryana).

\section{Patient population}

Sixty female patients scheduled for hysterectomy were screened and enrolled in this study as per inclusion and exclusion criteria. The eligible patients were randomly divided into two study groups i.e. Group K and Group D with the help of computer generated sequence having 30 patients in each study group.

\section{Inclusion criteria}

Inclusion criteria were patients of female gender of 30-65 years of age scheduled for hysterectomy; patients had grade I and grade II physical status according to ASA (American Society of Anesthesiologists); patients fit for the surgical procedure after the pre-anesthetic evaluation; patients who gave written informed consent for participating in the study.

\section{Exclusion criteria}

Exclusion criteria were patients who ASA grade III and IV physical status; patients with hypersensitivity to study drugs, NSAID's group and transdermal patches; patients with history of skin diseases; patients with history of asthma, gastrointestinal disorder, blood dyscrasias, cardiovascular diseases, severe hepatic and renal disorders and other co-morbid conditions; patients with history of drug abuse; any contraindication for spinal anaesthesia.

\section{Drug intervention}

The details of all the participants were recorded in the standardized format. At the beginning of study, all patients had undergone general physical examination, systemic examination along with relevant investigations (Hb, TLC/DLC, BT/CT).

Group K [Ketoprofen group]- Ketoprofen patch (30 mg) was applied in group $\mathrm{K}$ patients $1 \mathrm{hr}$ prior to surgery for $24 \mathrm{hr}$ time period.

Group D [Diclofenac group] - Diclofenac patch (100 mg) was applied in group D patients $1 \mathrm{hr}$ prior to surgery for $24 \mathrm{hr}$ time period.

Patients were fasted for 12 hours before the day of surgery. The patch was applied on a dry, non-irritated, non-hairy area of skin on left shoulder in most of the patients and on back after cleaning the skin with spirit swab. The dose of an analgesic required for the relief of break through pain is called rescue dose. Patient whose VRS (verbal rating scale) score was $>2$ or VAS (visual analogue scale) $>5$ received Inj. Paracetamol I/V $1 \mathrm{gm}$ as a rescue analgesic through infusion.

\section{Clinical assessment}

Patients were assessed clinically in terms of efficacy with safety parameter. Clinical assessment was done postsurgery at 4, 8, 12, 16, 20 and $24 \mathrm{hr}$. time interval after application of patch.

\section{Efficacy assessment}

The patients were assessed for the drug response by the following parameters.

\section{Primary end points}

- $\quad$ Verbal rating scale (VRS) of 0 - 4 points. $^{7}$

- Visual analogue scale (VAS) of $0-10$ points. $^{8}$ 


\section{Secondary end points}

- Use of rescue medicine over a $24 \mathrm{hrs}$ time period post-operatively.

- Patient satisfaction score (Likert Scale) $)^{9}$

- Anxiety score (State-Trait Anxiety Inventory $(\mathrm{STAI})^{10}$

\section{Safety assessment}

Safety assessment was done by asking history and doing physical examination in both study groups. Local side effects like itching, redness, swelling and systemic side effects diarrhea, constipation, hematemesis, headache, dizziness, nausea, vomiting and generalized weakness were noted.

\section{Statistical analysis}

Data was expressed as mean \pm SEM unless specified otherwise. Both intragroup and intergroup statistical analysis was done. Intragroup analysis was done using repeated measures ANOVA. Intergroup analysis was done using unpaired ' $t$ ' test. Categorical data like incidence of adverse events and consumption of rescue analgesic in both the groups were analyzed using Chisquare test. A p $<0.05$ was considered as statistically significant.

\section{RESULTS}

The demographic profile of the patients in the two study groups was comparable as shown in Table 1 . The average age in Group K was $(49.9 \pm 7.89)$ and in Group D was $(52.7 \pm 8.72)$ in years and average weight was $(51.93 \pm 3.41)$ \& $(51.43 \pm 3.81) \mathrm{kg}$ in Group K and Group D respectively. The duration of surgery in group $\mathrm{K}$ was $129.8 \pm 19.9 \mathrm{~min}$ and group D 133.5 $\pm 20.4 \mathrm{~min}$ ( $\mathrm{p}>0.05)$.

\section{Table 1: Demographic profile in Group $K$ and Group} D.

\begin{tabular}{|lll|}
\hline $\begin{array}{l}\text { Demographic } \\
\text { variable }\end{array}$ & $\begin{array}{l}\text { Group K } \\
\text { Mean } \pm \text { SD }\end{array}$ & $\begin{array}{l}\text { Group D } \\
\text { Mean } \pm \text { SD }\end{array}$ \\
\hline Age (in years) & $49.9 \pm 7.89$ & $52.7 \pm 8.72$ \\
\hline Weight (in kg) & $51.93 \pm 3.41$ & $51.43 \pm 3.81$ \\
\hline $\begin{array}{l}\text { Duration of Surgery } \\
\text { (in min.) }\end{array}$ & $129.8 \pm 19.9$ & $133.5 \pm 20.4$ \\
\hline
\end{tabular}

Pain was assessed postoperatively using VAS and VRS score in both the groups. In group-K, mean VRS score at $4,8,12,16,20$ and $24 \mathrm{hr}$. time interval was $1.90 \pm 0.05$, $\begin{array}{lll}1.40 \pm 0.09, & 1.47 \pm 0.93, \quad 1.50 \pm 0.09, \quad 1.73 \pm 0.08 \quad \text { and }\end{array}$ $1.77 \pm 0.12$ respectively. In group-D, mean pain score (VRS score) at $4 \mathrm{hr}$. time interval post-operatively was $1.93 \pm 0.05$. Pain score at $8,12,16,20$ and $24 \mathrm{hr}$. time interval was $1.80 \pm 0.08,1.80 \pm 0.08,2.03 \pm 0.58,1.76 \pm 0.07$ and $1.67 \pm 0.13$ respectively. The mean VRS score in
Group $\mathrm{K}$ and Group D at different time interval is shown in Figure 1.

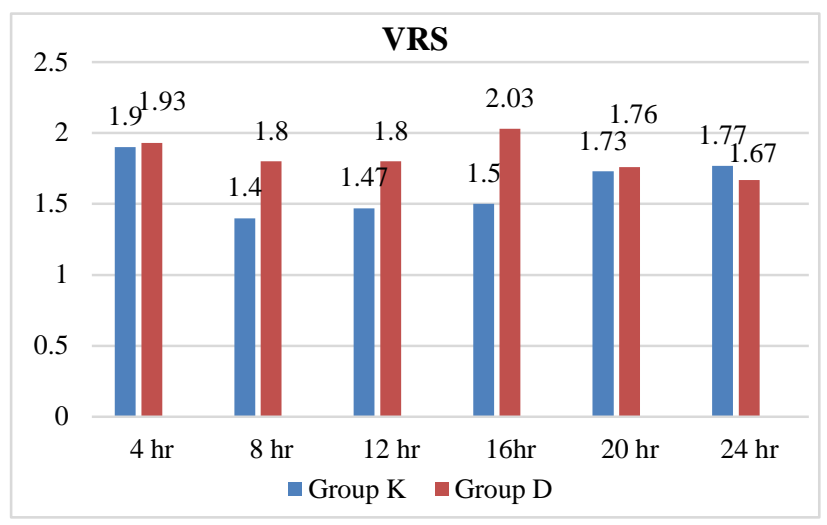

Figure 1: Intergroup comparison of VRS in group $\mathrm{K}$ and group $\mathrm{D}$.

When mean VRS score was compared between Group K and Group D, it was observed that difference in mean VRS score at 4, 8, 12, 20 and $24 \mathrm{hr}$ time interval was clinically significant but difference in mean VRS score was found statistically significant at $8 \mathrm{hr}$ and $16 \mathrm{hr}$ time interval only $(\mathrm{p}<0.05)$.

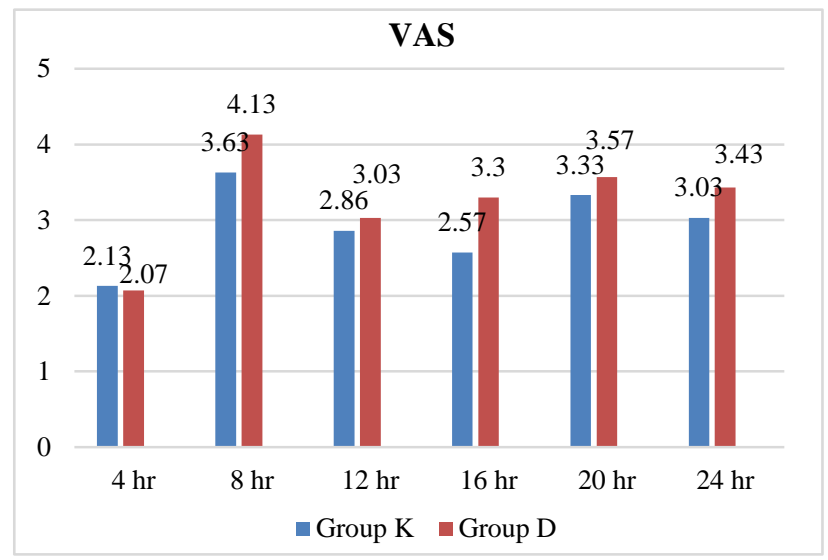

Figure 2: Intergroup comparison of VAS score in group $\mathrm{K}$ and group $\mathrm{D}$.

In group-K, mean pain score (VAS score) at 4, 8, 12, 16, 20 and $24 \mathrm{hr}$ time interval, post- operatively was $2.13 \pm 0.07,3.63 \pm 0.11,2.86 \pm 0.12,2.57 \pm 0.09,3.33 \pm 0.08$, $3.03 \pm 0.24$ respectively. In group-D, mean pain score (VAS score) at 4, 8, 12, 16, 20 and $24 \mathrm{hr}$. time interval was $2.07 \pm 0.15, \quad 4.13 \pm 0.09, \quad 3.03 \pm 0.08, \quad 3.30 \pm 0.18$, $3.57 \pm 0.14$ and $3.43 \pm 0.24$ respectively. The mean VAS score in Group K \& Group D at different time interval is shown in Figure 2.

The difference in mean VAS score was found statistically significant at $8 \mathrm{hr}$ and $16 \mathrm{hr}$ time interval only $(\mathrm{p}<0.05)$.The peak analgesic effect was achieved between $8 \mathrm{hr}$. to $16 \mathrm{hr}$. time interval in both the study groups. 
The consumption of rescue analgesic was comparable between both the groups. In group K, 3 patients and in group D, 6 patients required rescue analgesic and there was no statistical significant difference $(p>0.05)$ was present. The two groups were comparable regarding patient satisfaction score, anxiety score and autonomic pain component (systolic blood pressure, diastolic blood pressure and heart rate). No statistical significant difference was present. Systemic side-effects were mild in both the groups and there were no serious adverse effects observed in either of the study groups. In group $\mathrm{K}$, $16.66 \%$ patients complained of nausea and $10 \%$ patients complained of vomiting which was less as compared to group D in which, 30\% complained of nausea and $20 \%$ complained of vomiting. $16.66 \%$ complained of headache in both the study groups. However, none of the patients complained of local side effects like redness, itching and swelling in both the groups.

\section{DISCUSSION}

The management of post-operative pain remains an area for never ending research with better formulations and modalities continuously replacing present ones. Despite the fact that analgesic drugs are given through different routes as post-operative analgesia still there is a search for an ideal drug and route that can provide maximum analgesia, minimum side effects and improves patient compliance. Transdermal route is one of the most innovative drug delivery system which provide sustained drug delivery, needs single application a day and convenient to use. In addition, transdermal patch has other advantages like painless techniques, increased bioavailability, self-administration and easy termination of medication leading to better patient compliance. ${ }^{11}$ Transdermal patch is a medicated adhesive patch that is placed on the skin to deliver a specific dose of medication through the skin into blood stream. Therefore in the present study we have compared two drugs belonging to NSAIDs given through this innovative method in postoperative hysterectomy patients.

Transdermal drug delivery system is a very good method of pain management in postoperative period as it avoids the first pass metabolism and gastrointestinal complications associated with oral route and pain associated with i.m. or i.v. route.

NSAIDS are the commonly used drug for postoperative analgesia. The efficacy of NSAIDs in reducing pain is largely a result of their capacity to inhibit cyclooxygenase 1 and 2 (COX-1 and COX-2) key enzymes in prostaglandin biosynthesis. In the present study, ketoprofen and diclofenac were used as analgesic drug during hysterectomy in form of patch. The dose of ketoprofen patch and diclofenac patch used was $30 \mathrm{mg}$ and $100 \mathrm{mg}$ respectively. The patches were applied once for $24 \mathrm{hrs}$. In our study, pain was assessed postoperatively after every 4 hours for a period of 24 hours duration using VAS and VRS score. A VAS score of more than 5 and
VRS score of more than 2 were considered as a need for rescue analgesics.

In our study, when VAS was compared in both the groups it was observed that VAS $(2.92 \pm 0.11)$ in group $\mathrm{K}$ was significantly low as compared to group D (3.25 \pm 0.14$)$. Reetu $\mathrm{V}$ et al observed in their study in 60 patients who had orthopedic surgery on their lower limb that VAS in group $\mathrm{K}$ and $\mathrm{D}$ was $(1.4 \pm 0.3)$ and $(2.4 \pm 0.72)$ respectively. ${ }^{12}$ Kawai et al also observed that ketoprofen patch was more efficacious for relieving persistent local joint pain in patients with rheumatoid arthritis than placebo in their study. ${ }^{13}$ Franscisco and colleagues observed ketoprofen patch was better in reducing baseline pain in benign sports related soft tissue injuries. ${ }^{14}$ The result showed that NSAIDs patches are better in providing pain relief and ketoprofen patch was more effective then diclofenac patch as analgesic. The result of meta-analysis done by Sarzi-Puttini et al showed a statistically significant difference in the efficacy of ketoprofen versus diclofenac and ibuprofen. Ketoprofen was found to be more efficacious as compare to both diclofenac and ibuprofen in relieving pain and improving functional status of patients. ${ }^{15}$ Alessandri et al observed lower mean intensity pain score on VAS in diclofenac patch group as compared to placebo in patients undergone laproscopic surgery. ${ }^{16}$ Bhaskar et al concluded from their study that patch was as potent as oral diclofenac tablet in providing pain relief but has better patient compliance and can be used routinely as post extraction analgesia. ${ }^{17}$ Mazieres et al found that efficacy and tolerability in ketoprofen group was better as compared to placebo in reducing ankle sprain. $^{18}$ Kumar et al found lower VAS score in ketoprofen patch group in attenuating the pain during venous cannulation as compared to control group. ${ }^{19}$

In our study, when VRS was compared after $24 \mathrm{hrs}$ in both the groups it was observed that mean VRS $(1.62 \pm 0.22)$ in group $\mathrm{K}$ was significantly low as compared to group D $(1.83 \pm 0.16)$. The result of our study assessed by VRS showed that ketoprofen patch was better as postoperative analgesic in hysterectomy patients. Narzaree et al concluded that transdermal diclofenac patch reduced post-operative pain effectively with minimum side effects as compared to i.m. diclofenac in patients with inguinal hernia surgery as assessed by VAS and VRS. ${ }^{20}$

In present study, three patients in Group $\mathrm{K}$ and six patients in Group D required rescue analgesic in 24 hours. There was no statistical significance was present on comparison of rescue analgesic in our study. Safety analysis revealed no apparent serious adverse effects. In present study no local side effects was present at the application site as the patch was applied only for a single day. The most common adverse effects complained were headache, nausea and vomiting.

The strength of present study was that we used standard, validated scales during our study for assessing pain relief. The assessment of pain relief was done as per VAS and 
VRS scoring. To best of our knowledge no studies have assessed patient satisfaction score, anxiety score and changes in the autonomic pain component with pain scoring in the same study.

Our study has the limitation that the study sample was small. The analgesic patch was applied for a single day and the assessment was done for duration of $24 \mathrm{hrs}$ postoperatively. The result of our study does not reflect about a whole geographical region.

\section{CONCLUSION}

The present study concluded that transdermal patches are very convenient to use, cause less discomfort as compared to traditional routes of drug delivery. Ketoprofen patch was found better in providing analgesia after hysterectomy as compared to diclofenac patch with lesser side effects.

Funding: No funding sources

Conflict of interest: None declared

Ethical approval: The study was approved by the Institutional Ethics Committee

\section{REFERENCES}

1. Merseky H, Alberessard DC, Bonica J. J Pain terms A list with definitions and notes usage. Pain. 1979;6:249-52.

2. Debono DJ, Hoeksema LJ, Hobbs RD. Caring for Patients with Chronic Pain: Pearls and Pitfalls. J Am Osteopathic Assoc. 2013;113(8):620-7.

3. What should be the core outcomes in chronic pain clinical trials? Arthritis Res Therap. 2004;6(4):151-4.

4. Schimer BD. Pain management and conscious sedation. In: Mattox BE, editors. Sabiston textbook of surgery. The biological basis of modern surgical practice Philiadelphia: WB Saunders. 16th ed. 2001: 283-291.

5. Aida S, Baba H, Yamakura T, Taga K, Fukuda S, Shimoji K. The effectiveness of preemptive analgesia varies according to the type of surgery a randomized, double-blind study. Anesth Analg. 1999;89:711-6.

6. Calderon M, Guillermo C, Emina P. Postoperative pain management after hysterectomy- a simple approach. In: Hendy AA. Hysterectomy. 1 ed. London. 2012: 269-282.

7. Cork R, Issac I, Elsharydah A, saleemi S, Zavisca F, Alexander L. A comparison of the verbal rating scale and the visual analog scale for pain assessment. Internal J Anaesthesiol. 2003;8(1):1.

8. Crichton N. Visual analogue scale (VAS). J Clin Nurs. 2001;10(5):706.

9. Likert, Rensis. A Technique for the measurement of attitudes. Arch Psychol. 1932;140:1-55.

10. Adesanmi A, Afolabi M, Aramide F, Femi O. Assessment of preoperative and postoperative anxiety among elective major surgery patients in a tertiary hospital in Nigeria. M.E.J. ANESTH. 2015;23(2).

11. Singh MC, Naik AS, Sawant SD. Transdermal drug delivery systems with major emphasis on transdermal patches: A Review. J Pharm Res. 2010;3(10):253743.

12. Verma R, Kumar S, Goyal A, Chaudhary A. Comparison of single dose transdermal patches of diclofenac and ketoprofen for postoperative analgesia in lower limb orthopaedic surgery. Int J Res Med Sci. 2016;4(3):718-21.

13. Kawai S, Uchida E, Kondo M, Ohno S, Obata J, Nawata Y, et al. Efficacy and safety of ketoprofen patch in patients with rheumatoid arthritis: A randomized, double-blind, placebo-controlled study. J Clin Pharmacol. 2010;50(10):1171-9.

14. Esparza F, Cobian C, Jimenez JF, Garcia-Cota JJ, Sanchez C, Setrade AM, et al. Topical ketoprofen TDS patch versus diclofenac gel: Efficacy and tolerability in benign sport related soft-tissue injuries. Br J Sports Med. 2007;41(3):134-9.

15. Sarzi-Puttini P, Atzeni F, Lanata L, Bagnasco M. Efficacy of ketoprofen vs. ibuprofen and diclofenac: A systematic review of the literature and metaanalysis. Clin Exp Rheumatol. 2013;31(5):7318.

16. Alessandri F, Lijoi D, Mistrangelo E, Nicoletti A, Crosa M, Ragni N. Topical Diclofenac patch for postoperative wound pain in laparoscopic gynecologic surgery: A randomized study. J Minim Invasive Gynecol. 2006;13:195-200.

17. Bhaskar H, Kapoor P, Ragini. Comparison of transdermal diclofenac patch with oral diclofenac as an analgesic modality following multiple premolar extractions in orthodontic patients: A cross over efficacy trial. Contemp Clin Dentistr. 2010;1:158-63.

18. Mazieres B, Rouanet S, Velicy J. Topical ketoprofen patch $(100 \mathrm{mg})$ for the treatment of ankle sprain: a randomized, double-blind, placebo-controlled study. Am J Sports Med. 2005;33:515-23.

19. Kumar S, Sanjeev O, Agarwal A, Shamshery C, Gupta R. Double blind randomized control trial to evaluate the efficacy of ketoprofen patch to attenuate pain during venous cannulation. Korean J Pain. 2018;31:39-42.

20. Narzaree P, Griwan MS, Singh J. Efficacy and safety of transdermal diclofenac patch versus intramuscular diclofenac injections in postoperative patients of inguinal hernia. Int $\mathrm{J}$ Basic Clin Pharmacol. 2016;5:447-52.

Cite this article as: Rani S, Savant M, Mahendru R, Bansal P. Comparison of efficacy and safety of ketoprofen patch versus diclofenac patch as postoperative analgesic in hysterectomy patients. Int J Basic Clin Pharmacol 2019;8:2445-9. 